\title{
Numerical Simulation of Electric Powertrain for Examining Real World Performance of EVs at Sub-Zero Temperatures
}

\author{
Authors: Mohammad Tahir Baig and Stephen Samuel
}

\begin{abstract}
Electric Vehicles (EVs) are considered to be a worthy alternative to automobiles powered by internal combustion engines to achieve the goal of sustainable transportation. For their many known advantages, Li-ion cells are considered to be the most practical energy storage solution for the purpose of EVs propulsion currently. The capability of Li-ion cells to store energy in extreme cold operating temperatures is significantly lower than that at nominal operating temperatures due to greater power losses at cold temperatures. Therefore, it leads to degradation of performance of EVs in sub-zero temperatures.
\end{abstract}

The present work proposes a novel approach to use numerical simulation technique to build an EV model based on BMW i3 using GT Suite at sub-zero temperatures. The model is validated against experimental data obtained from Argonne National Laboratory for US06, HWY and UDDS legislative drive cycles. A real-world drive cycle representing real-world driving in Oxford, United Kingdom, was used for evaluating the effect of cold temperatures on the performance of the Electric vehicle. This paper presents the methodology followed for modelling an electric vehicle that represents BMW i3 EV, the scheme used for modelling the battery characteristics to include the effect of temperature and the resulting state of charge, internal resistance, efficiency, terminal current and power, energy consumption and loss characteristics at low ambient temperatures.

\section{Background}

Internal Combustion Engine (ICE) vehicles have been the primary propulsion technology for more than 120 years. With the rising number of automobiles on the roads, their emissions in the form of $\mathrm{CO}_{2}$ and other pollutants along with low working efficiency of our transportation (an average working efficiency of around $40 \%$ to $50 \%$ ), is a concern that needs immediate addressal [1]. In the last century or so, the automotive industry has seen very incremental changes, especially in the powertrain propulsion space. This has led to our unprecedented dependence on fossil fuels which, not only has empowered people with affordable personal transportation solutions, but also posed a few negative consequences.

Policy makers of major economies around the world, prominent environmentalists and engineers have recognized these concerns and are now advocating for a paradigm shift towards more sustainable

Page 1 of 16 solutions for our transportation needs. The industry believes that energy in the form of electricity is a viable alternative solution to fuel. Emadi [2] has stated that this shift towards electric mobility has been happening since early 1990s. The rapid improvements to power electronics (electric convertors, circuitry etc.) meant that processing electricity has become much more efficient and less complex thus giving electric mobility a boost.

Upcoming and currently available battery technologies for propulsion in EVs were assessed on the basis of performance and safety and found that Li-ion fulfilled most of the requirements for a sufficient and reliable battery storage solution in both short and long terms [3]. Higher specific energy capacity, longer service life, higher charge/discharge cycles, lower self-discharge and higher efficiency over the current lot of battery technologies propel Li-ion as the most desirable battery technology found in EVs today and in the future.

As EVs are an emerging technology that, in spite of witnessing massive popularity in recent times, are still witnessing major developments. This also means that the legislations and standards that assess EVs are also in their infancy and need major development. At present, SAE J1634 [4] is one of the latest standards for EV performance assessment. It details an approach that specifies the testing of EVs for both range and energy consumption. However, it has been pointed out by many researchers that such testing is not a true representation of real-world conditions, particularly for sub-zero temperatures. Moreover, Reyes et al. [5] points out that the testing strategy adopted in the standard is impractical when subjecting to a wide range of temperatures and operating conditions which normally exists in the real world (especially cold temperatures).

JRC in its technical report "Standards for performance and durability assessments of EV" in 2018 [6] detailed standards present all over the world regarding EV battery performance assessment both on system level (battery pack) as well as component level (cell level) and noted some essential points in the current scheme of things.

The report explicitly mentions that although various standards agree well with each other, the test conditions for charge and discharge rates should be as close to real life scenario as possible to predict a robust estimation of performance which is clearly missing in current standards. The standards for Battery Electric Vehicles (BEVs) are very closely set up with that of Light Electric Vehicles (LEVs) which requires a thorough corroboration that this is the ideal solution. Moreover, current standards have very limited usefulness when 
different versions of traction batteries are assessed, for instance, long/short range batteries. Additionally, an essential remark the technical report points out is that, the current standards are inclined more towards battery chemistry rather than system level assessment, which can be an issue when new technologies arrive which is quite possible as electric mobility is a dynamically evolving field.

This system level macroscopic investigation of BEVs in different operating scenarios, as mentioned by the JRC report, is missing in the current BEVs legislations and literature which this study aims to tackle using numerical simulation approach.

In spite of many desirable performance characteristics, Li-ion batteries, like lead acid, are very sensitive to ambient temperatures [7]. Researchers for years now have published work that investigate Li-ion performance degradations in sub-zero temperatures. Study conducted on a battery model built by Chan [8] showed that internal resistance of a battery is directly proportional to variations in ambient temperatures. Keeping this in mind, simulations on an electrothermal EV model, conducted by Jaguemont et al. [9], found that energy delivered by the same Li-ion battery reduced by up to $39.4 \%$ at $-20^{\circ} \mathrm{C}$ compared to $25^{\circ} \mathrm{C}$, leading to reduced $\mathrm{EV}$ range.

Tests conducted on real world test beds involving an actual vehicle also showed a similar trend of reduction in battery performance. Two popular EV models in the market were driven-to-depletion [5] in Winnipeg, Canada which experiences a broad range of temperatures $\left(-26^{\circ} \mathrm{C}\right.$ to $\left.28^{\circ} \mathrm{C}\right)$ throughout the year on particular days at a difference of $10^{\circ} \mathrm{C}$. Maximum distance was recorded $162-165 \mathrm{~km}$ at $25-28^{\circ} \mathrm{C}$ while least range was $48-55 \mathrm{Km}$ at -15 to $-26^{\circ} \mathrm{C}$ which is a reduction of $30-35 \%$. Usage of cabin HVAC puts additional stress on the ESS of the vehicle in cold temperatures which results in further reduction in range.

EVs shortcomings in diverse conditions, particularly in cold temperatures is quite evident from the literature widely available. An interesting point to note here is that, not only EVs but traditional ICE vehicles also perform poorly in extreme cold weather compared to their ideal conditions [10]. Lower temperatures cause engine oil to become more viscous which makes circulation more difficult, air becomes denser in winters which has adverse effects on the air/fuel ratio [1]. In spite of this, since ICE have been here for a while and thanks to engineering advancements, this form of propulsion has evolved to become more mature and reliable that these perceived problems are not considered as issues anymore because of a few established adaptations and modifications in place. For instance, electric block heaters are a common arrangement in cars in cold weathers to lessen these shortcomings. Eventually, EVs will also come up with their own adaptations, like this battery heating circuit that aids in the charge/discharge performance of batteries at low temperatures [11]. For that to happen, real world performance of EVs in sub-zero temperatures should be understood and critically analyzed first. This will also help, to some extent, set up better and more robust standards for EVs that address the system level macroscopic testing which is also mentioned explicitly by the JRC report [6]. Moreover, as it has been noted that without proper standards in place, potential of EVs and smoothness of its transition will be stunted [12].

Unfortunately, there lies a knowledge gap in the available literature and current research is very active in this sphere. This paper aims to address this from a numerical simulation point of view by building, validating, evaluating and critically analyzing a simple electric vehicle model to investigate its real-world performance under

Page 2 of 16 extreme cold weather temperatures. The following sections will further discuss the effect of cold ambient temperatures on Li-ion cell electro-chemistry and internal resistance.

\section{Effect of cold weather on Li-ion cell electrochemistry}

Cold weather has a significant effect on Li-ion cell electrochemical behavior. The work of Shiao et al. [13] demonstrates reduced $\mathrm{Li}$-ion cells chemical and charge transfer activity, which reduces the ionic conductivity of electrolytes. Chemical experiments also show a 2-to3 -fold drop in ionic conductivity of electrolytes at $-20^{\circ} \mathrm{C}$ [14]. This causes a reduction in Li-ion diffusivity which is essential in a cell in order to generate current [13]. Fundamentally, electrolyte viscosity increases in cold weather which hampers li-ion conductivity and their ability to undergo diffusion. This automatically results in an increase in internal resistance because the impedance of li-ions to freely move inside the cell also increases [15].

Another variation in cell electrochemistry in cold temperatures is the increase of charge-transfer resistance. It has been observed that there was a three folds increase in charge-transfer resistance in a $\mathrm{LiFePO}_{4}$ cathode at $-20^{\circ} \mathrm{C}$ compared to room temperatures [16]. Lithium plating is another source of internal resistance generation in cold temperatures. Over time metallic lithium forms around the anode of li-ion cells during general operation. However, in cold weather when cell temperature drops, anodes undergo polarization due to which their potential will lead more towards graphite or other carbon anodes than to that of lithium metal [17]. This slows down the intercalation of lithium ions into the anodes, which in real-world translates to longer time for the battery to charge. Lithium plating is a general occurrence in every Li-ion cell; however, cold temperature escalates this process reducing the healthy operating life of the battery. Therefore, these variations in cell electrochemistry causes the cell to spend more energy to supply current than it normally would. The cell is less eager to give its power, which might even lead to failure in meeting the application demand.

\section{Internal Resistance of Li-ion cells in Cold Weather}

When studying EVs operation in extreme cold temperatures, macroscopic analysis of the system is required rather than cell level. Therefore, different individual variations that cause a hike in internal resistance due to sub-zero temperatures as discussed above, are of limited use, rather macroscopic variations of internal resistance are given more importance. This is also the point mentioned in the JRC report [6] as lacking from the current testing regulations mentioned earlier.

In light of this, Awarke et al. [18] built a combination of a vehicle dynamics model coupled with an electric circuit battery model, and a $3 \mathrm{D}$ electro thermal model to study the thermal behavior of battery under various urban and highway drive profiles. It predicted an increase in internal resistance and other electric circuit battery model parameters as a function of temperature and SOC and demonstrated a significant increase in internal resistance as temperatures dropped. Similarly, an electric circuit model based on the Thevenin model was built to conduct characterization tests on a Li-ion battery to measure its performance parameters under the influence of ambient temperatures [19]. The model estimated internal resistance to be around $0.15 \mathrm{ohms}$ when the ambient temperature was $10^{\circ} \mathrm{C}$ at $0 \%$ SOC. While internal resistance was observed to be around $0.01 \mathrm{ohms}$ 
at $35^{\circ} \mathrm{C}$ with a $90 \% \mathrm{SOC}$, thus showing how internal resistance varies with respect to SOC and ambient temperatures.

From the above literature it is clearly inferred that in order to estimate the battery characteristics and behavior in certain set of conditions, it is important to build a battery model that can capture battery performance output macroscopically on a system level when it is subjected to extreme temperatures.

\section{Choosing a Modelling Approach}

Unlike other areas of battery applications, battery modelling in electric vehicles should be able to combine itself with the full EV model to investigate its performance macroscopically. As Zhu et al. [20] explains, model-based design of complex systems requires one or more components to interact with each other for the purpose of information flow. For most applications, a battery model should be able to predict battery parameters during operation like current and voltage across its terminals etc.

There are a few requirements the models need to fulfil in order to be suitable for EVs use [21]-

- Model should be capable to predict EV range fairly accurately. Hence, the model should be able to estimate SOC for range calculation.

- $\quad$ EV operation is quite transient in nature. Therefore, the battery performance is also dynamically evolving with time and operating conditions. This demands for the model to be capable of real-time computations. Fast models are desirable over extremely accurate and complex models.

- EVs accelerate and decelerate rapidly which involves quick discharging stresses on the battery. A battery model should be able to capture this aspect.

- The models should be flexible to combine with a bigger EV dynamics and thermal model for real world simulations.

Primarily, battery models are divided into three categories based on complexity of the physical representation of electrochemistryElectrochemical models (White box models), Reduced Order and Equivalent electric circuit models (grey box models) and Empirical and Neural network models (Black box models) [22].

Electrochemical models are a physics-based modelling approach that are very deeply based on the electrochemistry of the Li-ion batteries. Electrochemical models although details lithium cell functioning explicitly, it leads to very high computational loads that is very resource intensive when real-time simulations are required like in EVs [21]. This has been addressed by introducing a modified version called reduced order models that regulate parameters based on the complexity needed. But such models are not diverse and suffer from accuracy loss [22]. Hence, they fail to find the right compromise between complexity and accuracy which has led researchers to turn towards a different modelling approach for Hybrid and EVs that fulfil most of requirements mentioned earlier.

\section{Equivalent Electric Circuit Models (EECM)}

EECM are a lumped parameter modelling technique where a combination of electric elements like resistors, capacitors and voltage source represent functioning of a Li-ion battery. For example, a series resistor performs the resistance duties of a separator in a cell. They do not present the electrochemical phenomenon that occurs inside the cell like electrochemical models, but can predict li-ion cell behavior and output in different operating conditions with reasonable compromise between accuracy and computational complexity which is what is essential for macroscopic study of EVs.

In view of this, Rincon-Mora et al. [23] proposed a simple $2^{\text {nd }}$ order EECM to predict runtime current and voltage characteristics of a battery. This model is compatible with not only $\mathrm{Li}$-ion but also $\mathrm{NiCd}$, NiMH, Lead acid and also Li-polymer cells. Given in figure $1(a)$,
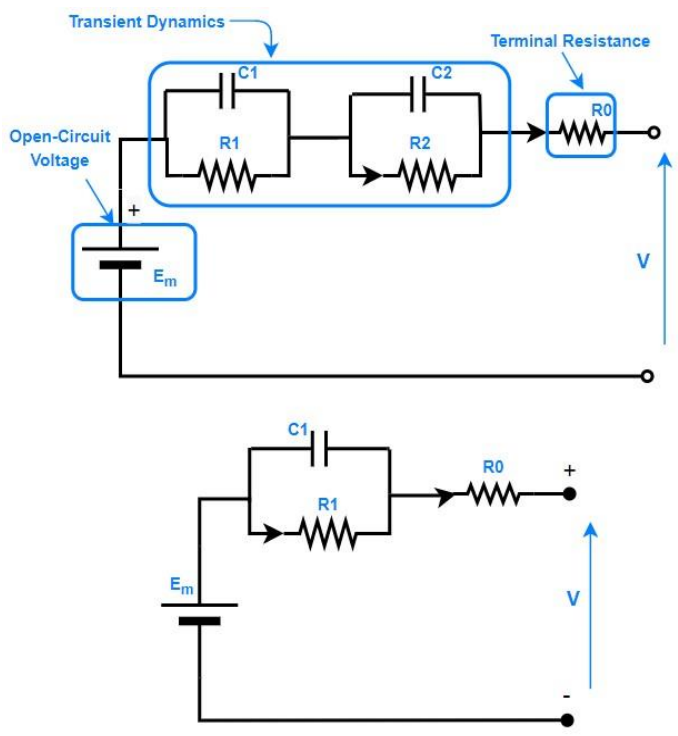

Figure 1. a) 2nd order EECM model and its functions based on [23], b) 1st order EECM model based on [9].

- a voltage source on the left represents the open circuit voltage $(\mathrm{OCV})$ of the cell,

- a series resistor on the right, $\mathrm{R}_{0}$, accounts for terminal voltage drop when load is connected,

- a network of one or more $\mathrm{RC}$ branches represents time constant frequency response of the battery. More RC branches result in higher accuracy but at the expense of complex parameter estimation and high computational loads.

- All the elements of the circuit behave non-linearly. Hence, they are represented as a function of SOC, temperature or even current, voltage preferably using lookup tables. This is how such models predict battery behavior when operating in cold weather.

Similarly, a $3^{\text {rd }}$ order EECM (with 3 RC circuits in series) was used with an added SOC estimation circuit that uses coulomb counting technique and includes effect of capacity-rate after long driving profiles [24]. Due to the presence of $3 \mathrm{RC}$ branches, the model was 
validated with great accuracy against an exhaustive dynamic EV driving simulator, although at the expense of high computational load.

Clearly, model order selection is a trade-off problem that is tackled based on accuracy needed and application demands. Hanlei et al. [25] conducted analysis of $1^{\text {st }}$ to $\mathrm{n}^{\text {th }}$ order EECM, found that there was a significant performance improvement until $3^{\text {rd }}$ order models beyond which model performance increments were negligible while complexity of simulation increased exponentially. A comparison of 12 different EECM models based on parameters like performance, accuracy, parameter estimation, computational load and simulation time was conducted [26]. The $1^{\text {st }}$ order EECM model was found to strike the best balance among other parameters considered in the literature. Adding to this, a $1^{\text {st }}$ order EECM was used to carry out macroscopic investigation of EV performance under the influence of hard winter temperatures and found to produce technically acceptable output under extensive validations [9] [27].

Therefore, keeping the above points in mind, an EV model is built using GT-Suite ${ }^{\mathcal{O}}$ numerical simulation software that represents the BMW i3 60Ah 2013 model, where the battery model is based on first order EECM. The parameters of the EECM are acquired from established literature. The model is then validated using Argonne National Laboratory's (ANL) dynamometer testing data of BMW i3 for different electric powertrain parameters [28]. Followed by validation, the BMW i3 numerical model is then investigated for performance evaluation using a custom drive cycle to replicate realworld conditions.

\section{GT-Suite Electric Vehicle Modelling}

A complete electric vehicle model is built in GT-Suite ${ }^{\odot}$ v2019 numerical simulation software to investigate cold weather performance of BMW i3. The vehicle model consists of vehicle body, axles, tires and brakes along with brake switch that is controlled by regenerative braking control logic, differential, final drive, environment subsystem and road object. This vehicle model is built using BMW i3 60AH 2013 model specifications [29]. Basic specifications are listed in Table 1.

\section{Vehicle Body}

The vehicle body model is needed to compute the longitudinal motion of the vehicle along with normal load acting on each axle during operation. Instantaneous longitudinal motion is computed using the resistive forces acting on the vehicle (tire rolling resistance, Aerodynamic drag, inertia components), tractive forces applied on the tires, road grade and wind velocity with direction. Therefore, the torque produced by the propulsion system is given in Eq. (1),
Table 1. BMW i3 EV Specifications [29].

\begin{tabular}{|c|c|c|}
\hline Specification & Value & Units \\
\hline Vehicle mass & 1443 & $\mathrm{Kg}$ \\
\hline Wheelbase & 2570 & $\mathrm{~mm}$ \\
\hline Drag Coefficient & 0.29 & ----- \\
\hline Frontal Area & 2.38 & $\mathrm{~m}^{2}$ \\
\hline Final Drive ratio & $9.7: 1$ & ------ \\
\hline Tire Specifications & $155 / 70$ R19 & ------ \\
\hline Rolling Resistance factor & 0.015 & ----- \\
\hline Differential Efficiency & 0.95 & fraction \\
\hline Axles Moment of Inertia & 1.25 & $\mathrm{Kg}-\mathrm{m}^{2}$ \\
\hline
\end{tabular}

$$
\begin{aligned}
T_{R}= & \frac{r}{i_{0} i_{\theta} \eta_{t}}\left\{\left(\frac{1}{2} \rho C_{d} A V^{2}+\left(m g \cos a-\frac{1}{2} \rho C_{L} A V^{2}\right)\left(f+K V^{2}\right)+\right.\right. \\
& \left.m g \sin a)+e m \frac{d v}{d t}\right\}
\end{aligned}
$$

Where, $r$ is the radius of the tire, $i_{0}$ is the final drive ratio, $i_{\theta}$ is the gear ratio, $\eta_{t}$ is transmission efficiency, $m$ is the vehicle mass, $V$ is the vehicle velocity, $\mathrm{g}$ is acceleration due to gravity.

\section{$\underline{\text { Inertia Co-efficient ' } \mathrm{e} \text { ' }}$}

The resistance caused due to inertia components have been represented by 'e' in the torque equation. Here, 'e' indicates the combined inertia of rotation due to engine and transmission and losses in the transmission system which is given in Eq. (2),

$e=1+\frac{I_{W}}{m r^{2}}+\frac{I_{t} i_{0}^{2}}{m r^{2}}+\frac{I_{e} i_{0}^{2} i_{\theta}^{2}}{m r^{2}}$

where, $\mathrm{I}_{\mathrm{w}}, \mathrm{I}_{\mathrm{t}}$, and $\mathrm{I}_{\mathrm{e}}$ are the moment of inertia of wheel, transmission and engine respectively.

\section{Aerodynamic Drag}

The torque equation also includes the losses caused due to aerodynamic friction given in Eq. (3),

$F_{d}=\frac{1}{2} \rho C_{d} A V^{2}$

where, $\rho$ is the density of air, $\mathrm{C}_{d}$ is the drag co-efficient, A is vehicle frontal area. 


\section{Tire Rolling Resistance}

Resistance caused due to deformation of tires is expressed as a function of load on the tires and rolling co-efficient $(\mathrm{Cr})$ in Eq. (4),

$F_{r}=m g \cos a C_{r}$

Additionally, lift co-efficient is also included in the model. Therefore, the vertical load on tires can then be represented as in Eq. (5),

$F_{r}=\left(m g \cos a-\frac{1}{2} \rho C_{L} A V^{2}\right) C_{r}$

Where, $C_{r}$ varies with speed of the vehicle $\left(C_{r}\right.$ increases as speed increases) and can be expressed as $\left(f+K V^{2}\right)$.

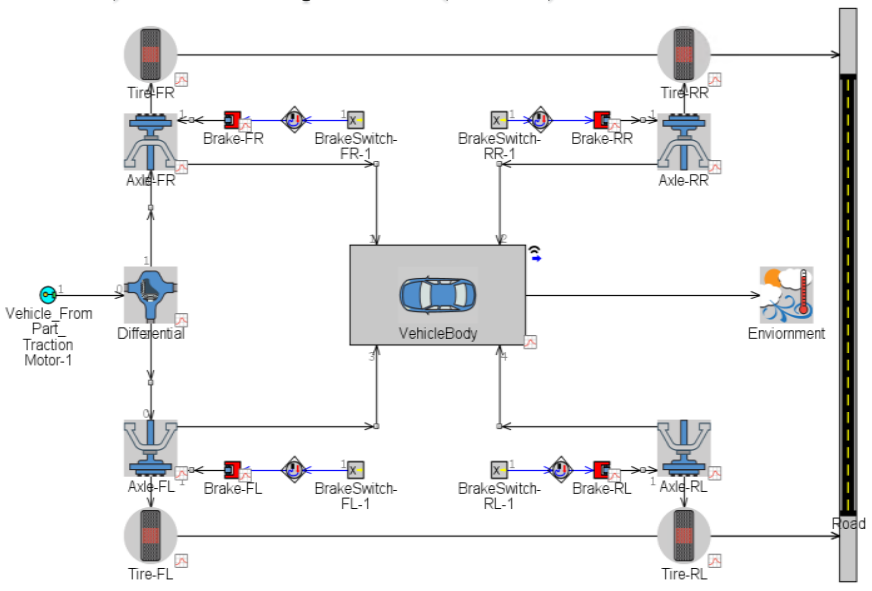

Figure 2. Vehicle Model modelled in GT-Suite.

\section{Electric Powertrain Modelling}

The electric powertrain subsystem includes a traction motor, battery pack, battery power limiter, regenerative braking model.

\section{Traction Motor}

The traction motor is modelled using 3D map-based traction motor efficiency and maximum/minimum torque curve maps of the BMW i3 60Ah that uses a permanent magnet synchronous motor with generator mode, given in table 2, for energy recuperation (regenerative braking). The motor is connected to a 1D mechanical domain (vehicle subsystem) using driveline shaft on one end and an electrical domain (battery pack) along with other auxiliary connections on the other. The control mode of the motor is brake torque controlled. To avoid complexity of simulation, thermal dependancy of the traction motor is ignored.

The torque output of the motor/generator map in the model is based on a 2D torque output map, as shown in figure 3, as a function of motor speed acquired from BMW i3 vehicle specifications [29]. Based on the tractive effort demanded by the drive schedule, the motor will produce torque according to this torque profile.
Table 2. EV Traction Motor Specifications [29].

\begin{tabular}{|c|c|c|}
\hline Electric Motor & Units & Value \\
\hline Peak Power output & $\mathrm{kW}(\mathrm{HP})$ & $125(170)$ \\
\hline Permanent power output & $\mathrm{kW}(\mathrm{HP}) / \mathrm{rpm}$ & $75(102) / 4800$ \\
\hline Torque & $\mathrm{Nm} / \mathrm{rpm}$ & $250 / 0$ \\
\hline Energy Recuperation & $\mathrm{kW}$ & Up to 50 \\
\hline
\end{tabular}

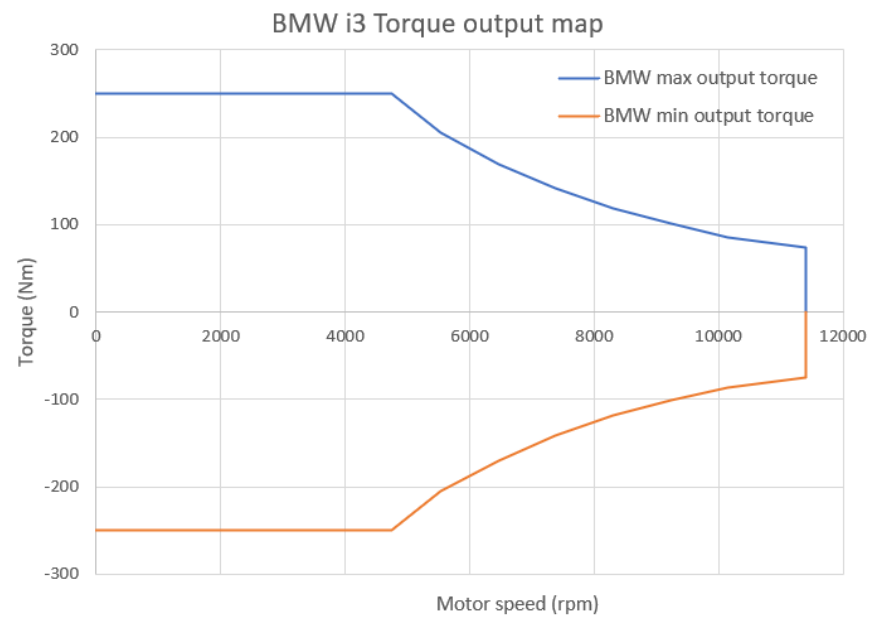

Figure 3. BWM i3 Motor Torque Curves [29].

\section{Regenerative Braking Model}

Energy recuperation is modelled using a simple control logic that works on the basis of different operating conditions of the model. An "IfThenElse" control object is used to define this control logic which accepts various real-time parameters of the vehicle and outputs the desired action based on the control logic. The main decision making in this model is whether friction brakes should assist in braking or deceleration be carried out by the traction motor generator's energy recuperation completely. Based on this decision making, brake switches are attached to each brake in vehicle model that operate friction brakes if needed, as shown in figure 2.

\section{Regenerative Braking Control Logic}

Inputs to the regenerative model are- 1) Actual Vehicle speed (VehSpeed) acquired from the vehicle model. 2) Torque Demand from Driver (TorqueDemand), based on drive cycle input. 3) Minimum Motor Torque (MinMotorTorque) maximum energy recuperation torque from traction motor map.

Given in Table 3, the first condition when vehicle is stationary, brake pedal is imposed to $100 \%$. In second condition, when maximum regen torque of motor is $10 \mathrm{Nm}$ (safety limit) more than torque demanded by driver, friction brakes are imposed based on brake torque vs pedal position 2D map. In rest all other cases of vehicle speed, third condition is activated where friction brakes are not used. 
Table 3. Regenerative braking model control logic.

\begin{tabular}{|c|c|c|c|c|c|}
\hline State & $\begin{array}{l}\mathbf{A} \\
\mathbf{c} \\
\mathbf{t} \\
\mathbf{i} \\
\mathbf{o} \\
\mathrm{n}\end{array}$ & Condition & $\begin{array}{l}\text { Brake } \\
\text { Mode }\end{array}$ & $\begin{array}{c}\text { Imposed } \\
\text { Brake } \\
\text { Pedal } \\
\text { Position }\end{array}$ & $\begin{array}{c}\text { Brake } \\
\text { Torque } \\
\text { Reques } \\
\text { t }\end{array}$ \\
\hline $\begin{array}{l}\text { Vehicle } \\
\text { stopped }\end{array}$ & $\begin{array}{l}\mathrm{I} \\
\mathrm{F}\end{array}$ & $\begin{array}{l}\text { VehSpeed }<0 \text { and } \\
\text { TorqueDemand }<0\end{array}$ & $\begin{array}{c}\text { Impose } \\
\text { brake } \\
\text { Pedal }\end{array}$ & $100 \%$ & 0 \\
\hline $\begin{array}{c}\text { Friction } \\
\text { Brake } \\
\text { Assist }\end{array}$ & $\begin{array}{l}\mathrm{T} \\
\mathrm{H} \\
\mathrm{E} \\
\mathrm{N}\end{array}$ & $\begin{array}{c}\text { TorqueDemand }<0 \text { and } \\
\text { MinMotorTorque }>\text { Tor } \\
\text { queDemand }+10\end{array}$ & $\begin{array}{c}\text { Impose } \\
\text { brake } \\
\text { Pedal } \\
\text { to } \\
\text { supple } \\
\text { ment } \\
\text { Regen } \\
\text { braking }\end{array}$ & $\begin{array}{c}\text { Brake } \\
\text { Torque } \\
\text { request } \\
\text { based on } \\
\text { Pedal } \\
\text { Position 2D } \\
\text { Map }\end{array}$ & $\begin{array}{c}\text { Torque } \\
\text { Demand } \\
- \\
\text { MinMot } \\
\text { orTorqu } \\
\text { e }\end{array}$ \\
\hline $\begin{array}{c}\text { No } \\
\text { Friction } \\
\text { Brakes }\end{array}$ & $\begin{array}{l}\mathrm{E} \\
\mathrm{L} \\
\mathrm{S} \\
\mathrm{E}\end{array}$ & $\begin{array}{c}\text { Rest all other } \\
\text { conditions of } \\
\text { VehSpeed }\end{array}$ & $\begin{array}{c}\text { Impose } \\
\text { brake } \\
\text { Pedal }\end{array}$ & $0 \%$ & 0 \\
\hline
\end{tabular}

\section{Battery Power Limiter}

In order to control the battery charging and discharging power limits of EECM battery model, a battery power limiter is used. It acts like a basic battery management system that suffices the needs of matching the battery output of model with the EV to a certain extent while ensuring safe current and voltage limits of battery defined by the RC branches.

A combination of feedforward and feedback controls dictate the power limits. For power calculations, the battery controller senses information such as OCV and internal resistance ( $\left.\mathrm{R}_{\text {int }}\right)$ of EECM battery automatically and computes power using the equation below.

Feed forward controller, Power $=(I O C V)-\left(I^{2} R_{\text {int }}\right)$,

Where, OCV is open circuit voltage and $\mathrm{I}=\frac{O C V-V}{\operatorname{Rint}}$ where $\mathrm{V}$ is obtained from voltage limit calculations. Voltage and current range are set by user. A PI controller modelled in the limiter then corrects the computed power to the voltage and current limits so as to remain within the range given by user.

\section{Battery Pack Modelling}

BMW i3 60Ah has a stated $18.8 \mathrm{KWh}$ Li-ion battery pack $(18.2 \mathrm{KWh}$ usable). The pack consists of 96 cells arranged in 8 modules with 12 cells in each module. The cells in each module and all 8 modules are connected in series [29]. Specifications of battery pack are given in table 4.

Page 6 of 16
The battery pack has been modelled as a first order EECM which has $1 \mathrm{RC}$ branch given in figure 1(b). The circuit parameters of EECM are modelled as a function of SOC, temperature and current in a lookup table acquired from established literature. Li-ion battery pack has been modelled as a lumped mass system, which means it has been modelled as a battery pack and not as group of modules or individual cells because the study is based on macroscopic variations and not on discrete effects on each module or cell.

Table 4. BMW i3 60Ah Battery Pack Specifications [29].

\begin{tabular}{|c|c|c|}
\hline Battery Pack & Units & Value \\
\hline Total cells & - & 96 \\
\hline Cells in Series/Parallel & $-/-$ & $96 / 1$ \\
\hline Cell Capacity & $\mathrm{Ah}$ & 60 \\
\hline Cell Nominal voltage & $\mathrm{V}$ & 3.7 \\
\hline Pack Capacity & $\mathrm{Ah}$ & 60 \\
\hline Pack nominal voltage & $\mathrm{V}$ & 355.2 \\
\hline Pack Power Gross/Useable & $\mathrm{kWh}$ & $18.8 / 18.2$ \\
\hline
\end{tabular}

\section{Battery Pack Scaling}

The single cell parameter of BMW i3 entered as inputs to the model is scaled up to form the battery pack using the equations below.

$\begin{array}{ll}\text { Battery pack Capacity, } & \text { Cap }_{\text {pack }}=N_{P} \text { Cap }_{\text {cell }} \\ \text { Open Circuit voltage, } & V_{\text {OC,pack }}=N_{S} \text { VOC,cell } \\ \text { Pack Resistance, } & R_{\text {pack }}=\frac{N s}{N p} R_{\text {cell }} \\ \text { RC time constants, } & t_{\text {pack }}=t_{\text {cell }} \\ \text { RC Capacitances, } & C_{\text {pack }}=\frac{N p}{N s} C_{c e l l}\end{array}$

Where, $\mathrm{N}_{\mathrm{p}}$ and $\mathrm{N}_{\mathrm{s}}$ are number of parallel and series cells respectively,

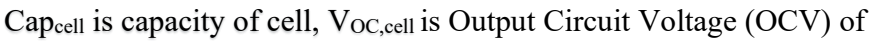
cell, $R_{\text {cell }}$ internal resistance of single cell, $\mathrm{C}_{\text {cell }}$ is capacitance of cell.

\section{SOC Modelling}

A conventional SOC modelling is used where instantaneous current (Ioc) through OCV is integrated over time to estimate change in capacity over time. Change in capacity is subtracted from the initial capacity (Capinit) to calculate the instantaneous capacity. 
Change in capacity, $\quad \operatorname{Cap}(t)=\operatorname{Cap}_{\text {init }}-\int_{0}^{t} I_{O C} d t$

Where, Initial capacity, $\quad$ Cap $_{\text {init }}=$ SOC $_{\text {init }}$ Cap $_{\max }$

$\left(\right.$ Cap $_{\max }=$ max capacity $)$

State of Charge, $\quad$ SOC $=\frac{\operatorname{Cap}(t)}{\operatorname{Cap}(\max )}$

\section{Circuit Parameters}

The circuit parameters for the first order RC EECM were acquired from the work of Jaguemont et al. [9]. In the paper, a battery was discharged at various temperatures in a climatic chamber to simulate cold temperatures and pulse characterization tests were performed. The cell is submitted to a partial discharge-rest cycles for a fixed amount of time. This process is repeated several times at different temperatures and at the end of each phase, circuit parameters $\mathrm{OCV}$, $\mathrm{R}_{0}, \mathrm{R}_{1}$ and $\mathrm{C}_{1}$ are acquired as a function of temperature and SOC using data acquisition systems and software tools mentioned in detail in their paper. The functions of each component in EECM are:

- $\quad$ OCV is captured by the rest phases between each pulse discharge that is modelled by the source voltage component (Em) in EECM.

- The instantaneous response is the instant drop in voltage to a pulse, modelled by the Ohmic resistor component $\left(\mathrm{R}_{0}\right)$ in EECM,

- Delayed response is stabilization of voltage after the pulse which is modelled by $\mathrm{RC}$ branch time constant $\left(\mathrm{R}_{1} \times \mathrm{C}_{1}\right)$ in EECM.

The circuit parameters for the battery in the current study were loaded in the numerical model as 3D maps. Open circuit voltage $(\mathrm{OCV})$ is represented as a function of SOC, it drops linearly until $20 \%$ SOC and falls sharply after. Terminal resistance component $\mathrm{R}_{0}$, is detailed as a $3 \mathrm{D}$ map based on temperature and SOC, where it is highest at $-20^{\circ} \mathrm{C}$ at SOC less than $20 \%$ and lowest when temperature is $25^{\circ} \mathrm{C}$ at SOC more than $10 \%$. Similarly, transient dynamics components, $C_{1}$ and $R_{1}$ are also represented as a function of temperature and $\mathrm{SOC}$ and follows a similar pattern.

An EECM captures the Li-ion battery behavior through its components. Therefore, even though a different battery is used in the literature, it captures the general cell behavior that is later scaled to represent BMW i3 battery pack. Therefore, when actual battery cell experimental data is not available, such as in this case, experimental data from established literature can also be used to conduct work.

\section{Driver Model}

This part models a vehicle driver which is intended to control the accelerator and brake pedal position. This part is used when dynamic drive cycle analysis is needed where the speed of the vehicle is controlled according to a $2 \mathrm{D}$ time vs vehicle speed driving schedule

Page 7 of 16 which is called a drive cycle. For such simulations, driver mode is set to speed targeting in which the accelerator and brake pedals are controlled to match the vehicle speed with drive cycle.

The model consists of a feed forward controller which computes the traction motor braking torque that is needed to achieve the target vehicle speed. The driver part automatically senses information from the electric powertrain sub-system to perform computations. A PID controller then makes corrections to minimize error between vehicle speed and drive cycle.

The numerical model schematic is given in Appendix Figure A1.

\section{Model Validation}

The model prepared in GT-Suite ${ }^{\odot}$ is now validated to establish the level of fidelity the model is able to achieve compared to actual BMW i3 60Ah car for performance in different ambient temperatures. This is done by validating the model simulation results with that of the experimental results acquired by Argonne National Laboratory (ANL). ANL has conducted dynamometer vehicle testing of BMW i3 60Ah model in a temperature chamber to simulate ambient temperatures for various legislative drive cycles [28].

Some prerequisite points regarding model validation are-

- $\quad$ Model validation is conducted for $-20^{\circ} \mathrm{C}$ and $25^{\circ} \mathrm{C}$ using ANL test data conducted at those temperatures.

- In the ANL test of $-20^{\circ} \mathrm{C}, \mathrm{HVAC}$ system of BMW i3 car was switched $\mathrm{ON}$. This would consume additional battery energy in the test other than the drive cycle load. Moreover, battery thermal management system of BMW i3 will also be functional at this temperature by default which consumes additional energy.

- In the ANL test of $25^{\circ} \mathrm{C}, \mathrm{HVAC}$ system was switched OFF. Therefore, there is no additional energy consumption from climate control system of vehicle. Other auxiliary systems, however, will continue to consume energy as normal, irrespective of ambient temperature.

- $\quad$ Tests are conducted for US06, UDDS and HWY driving schedules which have diverse characteristics. The diverse nature of these driving schedules is a contributing factor to the robustness of validation of the current model.

Some of the assumptions made in the current model are-

- To avoid complexity of modelling and parameter estimation, auxiliary systems like pumps or battery thermal management/cooling system are not included in the scope of this study.

- Due to the absence of auxiliary systems, the battery pack temperature in the model is considered to be same as that of the ambient temperature.

- Due to the absence of a Battery Thermal Management System (BTMS), the battery pack temperature is kept constant $\left(-20^{\circ} \mathrm{C}\right.$ and $\left.25^{\circ} \mathrm{C}\right)$ throughout each simulation. 


\section{Legislative Drive Cycles}

UDDS, HWY and US06 drive cycles represent diverse characteristics [30]. In figure 4, UDDS is a transient drive cycle with continuously varying acceleration and speeds throughout the range. However, it is not aggressive as the average acceleration and average speed are just $0.47 \mathrm{~m} / \mathrm{s}^{2}$ and $31.5 \mathrm{Km} / \mathrm{h}$ respectively. UDDS is approximately 11.98 $\mathrm{Km}$ long and lasts 1369 seconds and is suitable for simulating city or urban conditions [30]. HWY is a high-speed drive cycle simulating a typical expressway behavior of vehicles as shown in figure 4. Its average speed is $78 \mathrm{~km} / \mathrm{h}$ and average acceleration is a low $0.18 \mathrm{~m} / \mathrm{s}^{2}$. It is $16.5 \mathrm{Km}$ and 765 seconds long [30]. Such a drive cycle is used to test the steady cruising behavior of automobiles on high-speed expressways. US06 is the most aggressive driving profile among the three shown in figure 4. It is also a high-speed profile with massive variations in acceleration. Its average speed is $79.62 \mathrm{Km} / \mathrm{h}$ and average acceleration is a high $0.541 \mathrm{~m} / \mathrm{s}^{2}$ [30]. It is, however, not as transient as UDDS, neither as steady state as HWY and is approximately $12.89 \mathrm{~km}$ and 600 seconds long. Such an aggressive profile adds additional load on the powertrain.

These driving profiles will test the transient, steady cruising as well as aggressive response of the current model against the experimental data of ANL for different temperatures.

\section{Validation of the Numerical Model}

Validation for speed profile- To ensure the electric powertrain of the model is capable to propel the EV according to the drive schedule, simulation data of the model speed is compared to the drive cycles.

From figure 4 the model can be seen to follow the speed profile with less than $2 \%$ error. The driver model, regenerative braking system, traction motor and battery pack are able to maintain the load of drive cycle without any time delays even on aggressive drive cycle like US06 and transient one like UDDS.

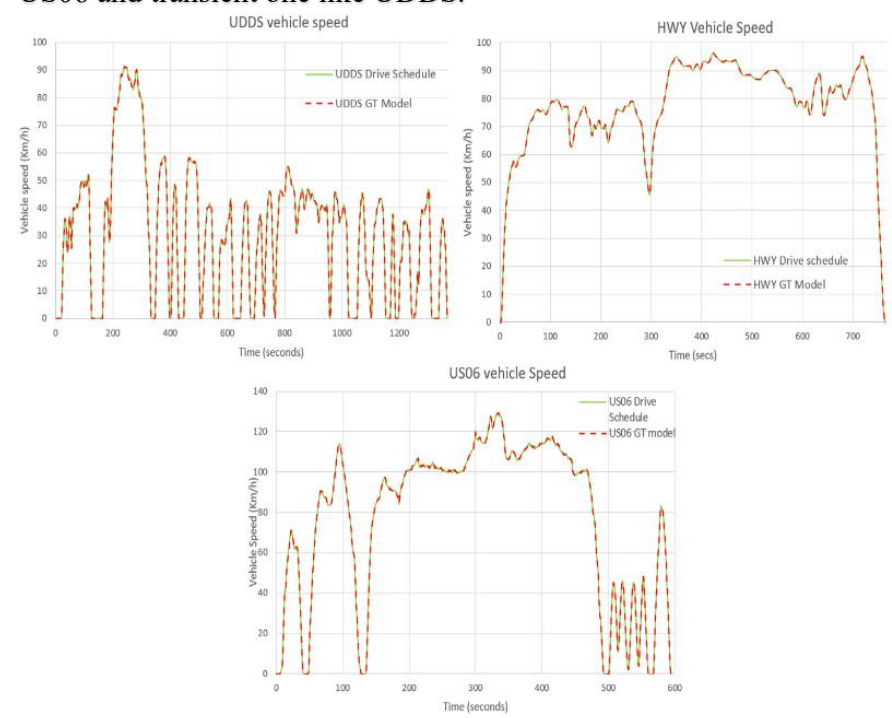

Figure 4. UDDS, HWY and US06 Drive cycles vs numerical model vehicle speed validation.

Page 8 of 16

\section{Validation for electric powertrain}

SOC-Validation for battery SOC at $25^{\circ} \mathrm{C}$ of the model shows a good agreement with ANL experimental data in figure 5(a). In spite of a fairly simple Coulomb counting technique for SOC estimation, the accuracy of the model is more than $95 \%$ on average for the three drive cycles at positive temperatures. The model follows the trend of SOC curve really well which substantiates the robustness of the SOC estimation model included in the battery model. The model predicts higher SOC value at the end of every cycle towards the end. This is due to the additional energy consumption by the actual BMW i3's auxiliary system in ANL testing compared to the current model.

Figure 5(b) shows the real time error between ANL and the current model SOC datapoints in terms of percentage for the length of the drive cycle. A higher order polynomial curve is fitted to the error datapoints to see the limits. It can be seen that the maximum error for the aggressive US06 cycle is around $2.5 \%$, while maximum error of HWY and UDDS is less than $2.5 \%$ and $2 \%$ from ANL data respectively. The average error computed for SOC between ANL and the numerical model for the length of the three drive profiles is $1.06 \%, 1.21 \%$ and $1.51 \%$ for UDDS, HWY and US06 respectively. Overall, the current Model varies from ANL test data by an overall average of $1.21 \%$ at positive temperatures.

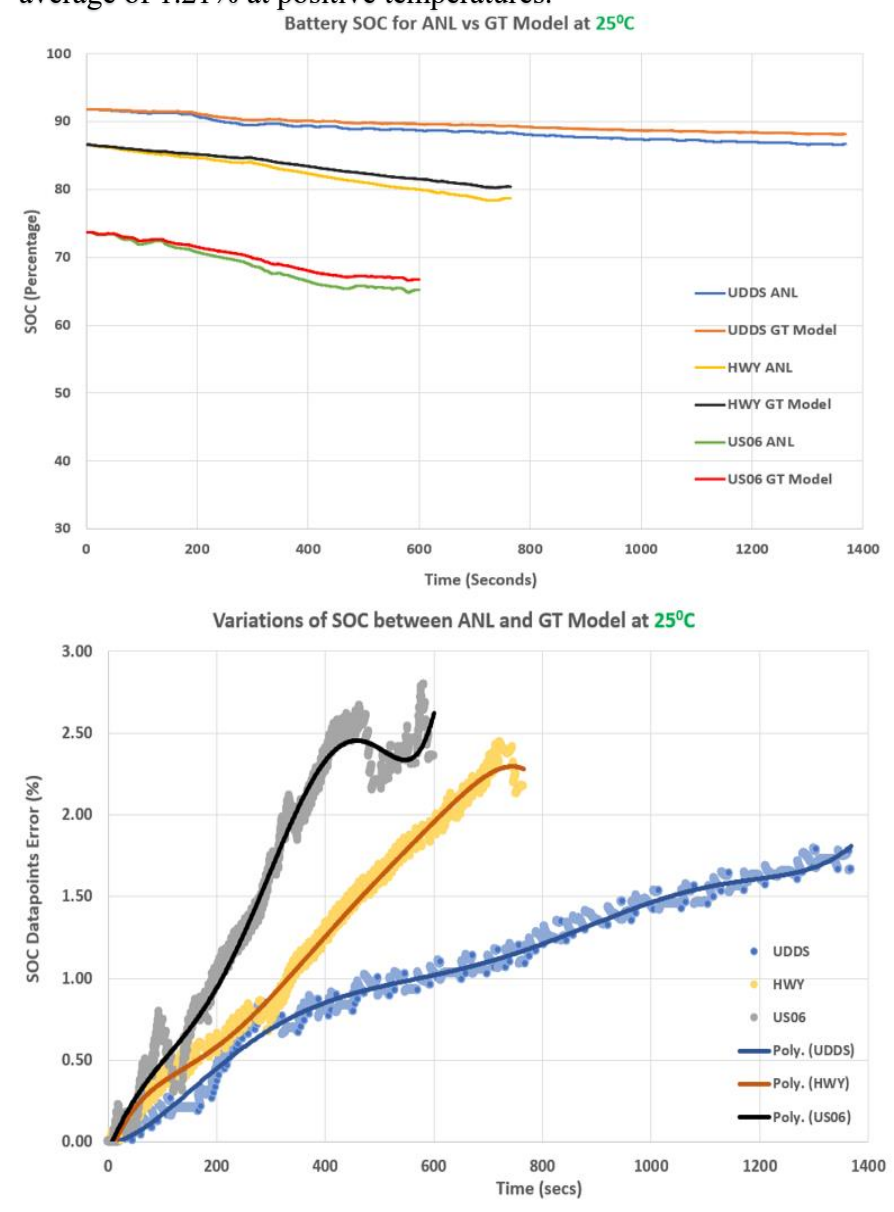

Figure 5. a) ANL vs numerical model SOC at $25 \mathrm{C}$ for different drive profiles, b) Variations in $\%$ of SOC data ANL vs numerical model at $25 \mathrm{C}$. 
At $-20^{\circ} \mathrm{C}$, the difference for UDDS cycle is larger than the other two cycles in figure 6(a). An interesting point to note here is that, the model performs well for high-speed HWY cycle. The accuracy is further improved for high speed aggressive US06 drive cycle.

When the drive schedule is high speed and aggressive (HWY, US06), the additional load on the battery compensates for the lack of HVAC system in the current model and results in a good agreement achieved at sub-zero temperatures. This is evident in figure 6(b), US06 model has the least variation in SOC datapoints compared to ANL at an average $1.48 \%$ for the full cycle, while average variation for HWY and UDDS is $1.41 \%$ and $2.9 \%$ respectively. Overall, for the three cycles, the numerical model varies from ANL data by $1.93 \%$ only at $20^{\circ} \mathrm{C}$. In summary, average error for ANL vs GT model SOC estimation is kept under $2 \%$ at $-20^{\circ} \mathrm{C}$ and $25^{\circ} \mathrm{C}$ proving that the numerical model predicts SOC very well which is sufficient for the scope of this study.
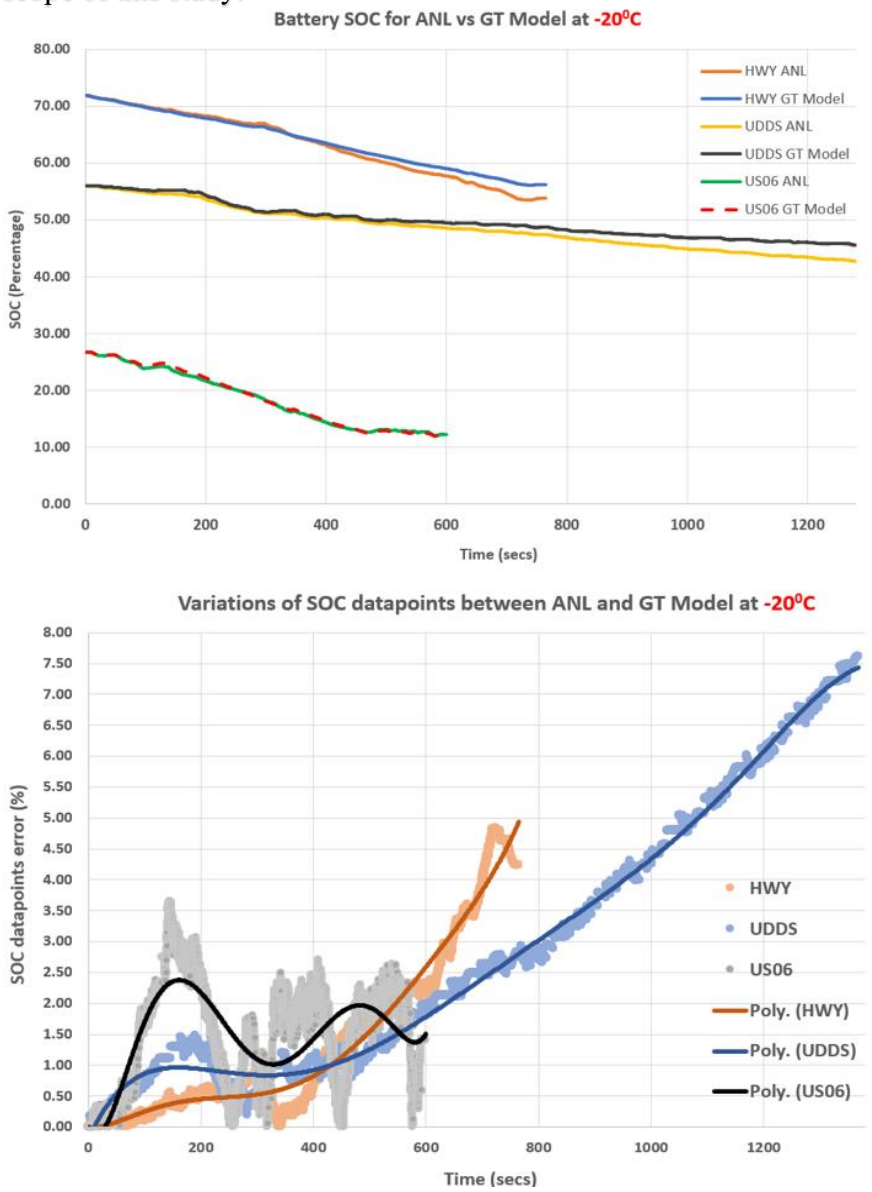

Figure 6. a) SOC comparison for ANL vs numerical Model at -20C, b) Percentage error in SOC datapoints of model vs ANL.

Terminal Current- Validation of current output requires the comparison of numerical model terminal current and ANL test data. For the purpose of validation, the major plots that capture a diverse set of conditions are included here.

Figure 7(a) shows the terminal current output for the UDDS cycle at $25^{\circ} \mathrm{C}$. For extremely transient applications, it can be seen that the model matches the current profile very well with the ANL test data.
There are certain instances where ANL data has additional peaks of current. This is because of persistent current supply to the auxiliary systems in ANL testing. In figure 7(b) the current data points of both datasets are expressed as percentile for better understanding. It can be seen that at negative current (during energy recuperation) the current data points of model and ANL are exactly similar, which demonstrates the soundness of the simple energy recuperation control logic described in above section. The trend of the percentile points throughout the range of current is quite similar to the actual car tested on dynamometer. Current data points agree well until the $65^{\text {th }}$ percentile mark.

There are a few discrepancies visible towards the upper set of around eight current data points (upwards of $65^{\text {th }}$ percentile) where the numerical model overpredicts current output. However, this discrepancy is computed to be less than $7 \%$ variation compared to ANL, when differences of those eight points were averaged. Such a match is acceptable at positive temperature considering the limited inputs given to the validated model.
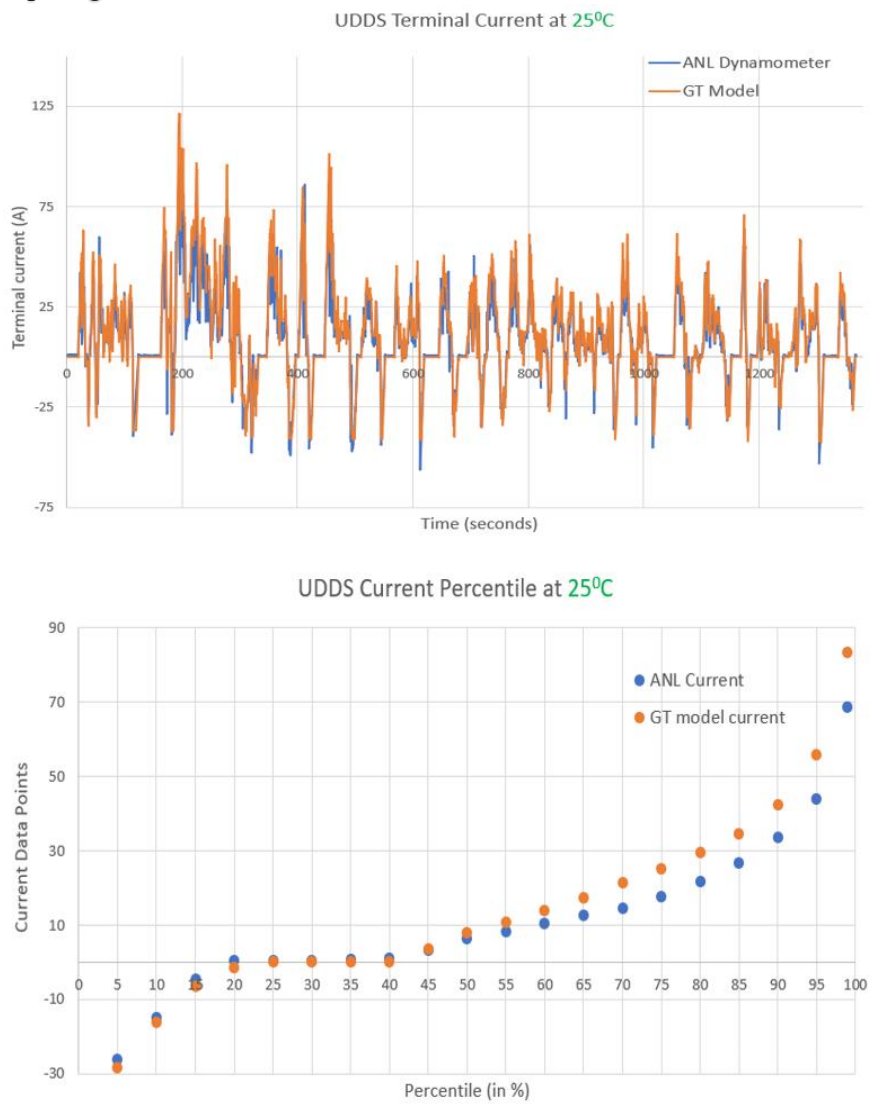

Figure 7. a) UDDS ANL vs numerical Model Current at 25C, b) UDDS Current Data points expressed in Percentile at 25C.

In Figure $8(a)$, at negative temperature of $-20^{\circ} \mathrm{C}$ as well, the model shows good agreement with the ANL terminal current data. The validation shown here is for the aggressive US06 cycle. In Figure $8(b)$, current datapoints are represented in percentiles. It can be seen that the current output of ANL and validated model match quite well throughout the entire current range. Even the negative current datapoints (energy recuperation) match well which demonstrates the regenerative braking model performance at negative temperature as

Page 9 of 16 
well. The data points are extremely accurate for 90 percentiles of the points, which is very good considering the high current demands for the US06 cycle.

Slight discrepancies occur towards the upper end, as can be seen in figure $8\left(\right.$ b). Maximum occurs at the $99^{\text {th }}$ percentile where the error is less than $10 \%$. Discrepancy is slightly higher than at positive temperatures which is because the HVAC system in the ANL vehicle is in operation at $-20^{\circ} \mathrm{C}$ that consumes current, which gets amplified when higher currents are demanded.

US06 is extremely transient with aggressive acceleration/deceleration in a span of less than few seconds after the $500^{\text {th }}$ second mark. Even in such aggressive and transient conditions, the numerical model matches ANL data with more than $88 \%$ accuracy of datapoints as shown in figure 9. An interesting point to note in figure $8(a)$, at certain instances when the vehicle is in rest, current of numerical model is zero while the ANL car has persistent current input. Such spots are marked with green circles. This is because the HVAC system is operational in $-20^{\circ} \mathrm{C}$ in ANL testing that consumes current continuously.
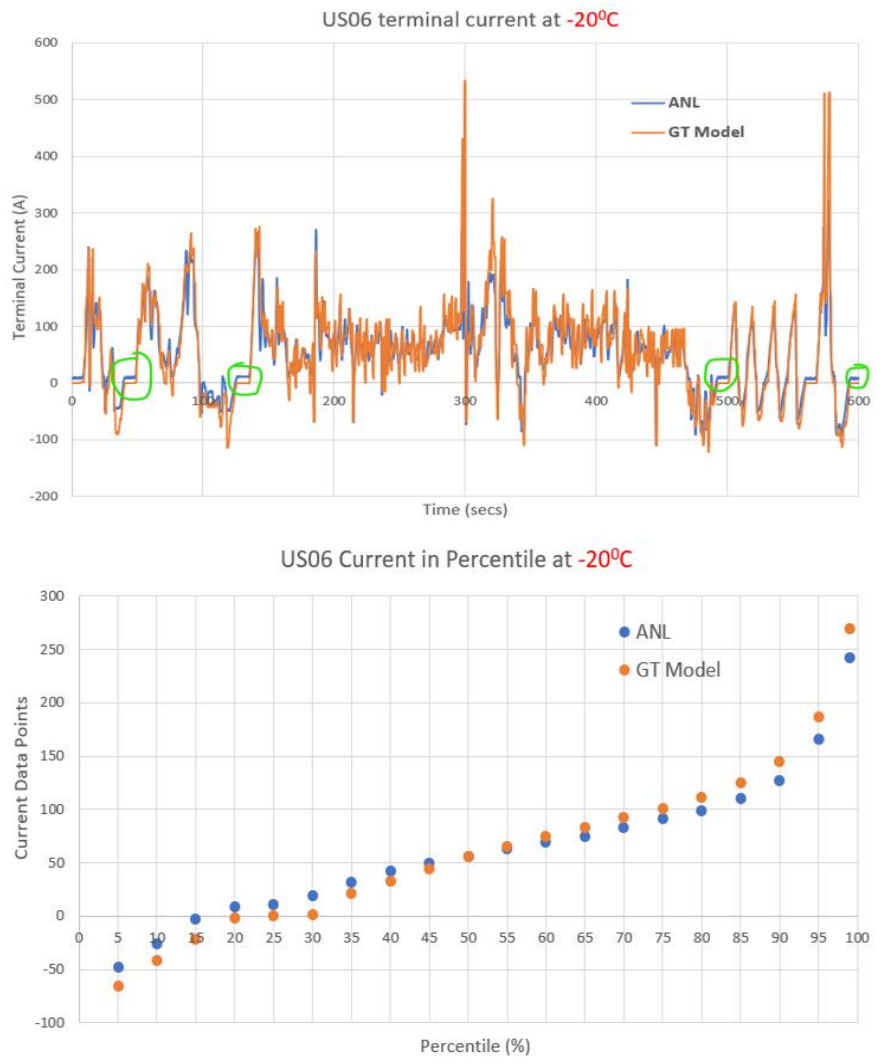

Figure 8. a) US06 Current output for ANL vs numerical model at $-20^{\circ} \mathrm{C}$, b) Current Output datapoints expressed in percentile at $-20^{\circ} \mathrm{C}$.

In conclusion, the numerical model predicts SOC with an error of less than $2 \%$ at both positive and negative temperatures compared to ANL test data. Current output of the numerical model also matches ANL data with an accuracy of $92 \%$. This output is comparable with the experiment data obtained from ANL [28]. The ANL experimental data showed negligible test to test variation at nominal ambient temperature of around $23^{\circ} \mathrm{C}$ and higher. However, at sub-zero Page 10 of 16 temperatures, the test-to-test variation is found to be around $10 \%$ [28]. The level of validation done is sufficient for the scope of this study and the numerical simulation model is now assessed for real world performance.

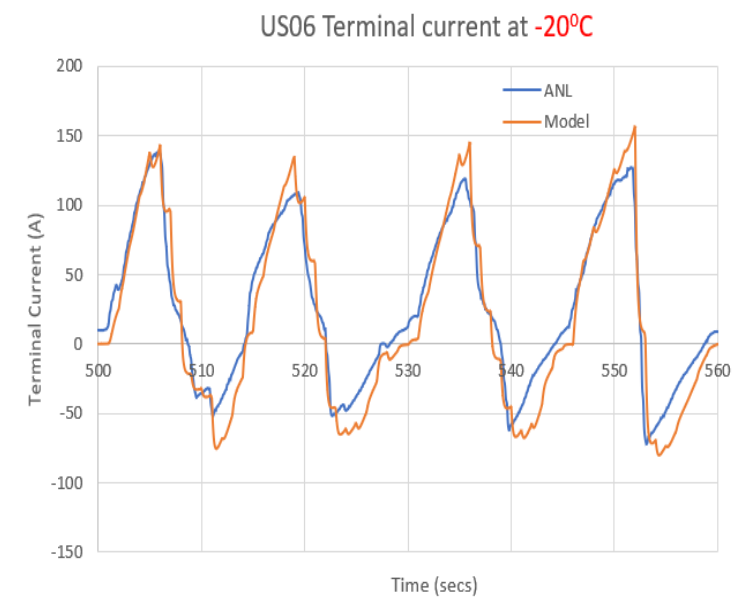

Figure 9. US06 terminal current after 500th sec at $-20^{\circ} \mathrm{C}$.

\section{Real World Performance}

\section{Real-World Drive Cycle}

The urban drive cycle used for this study represents typical driving pattern in Oxford UK. The drive cycle used here is largely based on city driving conditions with transient and aggressive characteristics at moderate speeds. This cycle is $23.23 \mathrm{~km}$ long and lasts for $2338 \mathrm{secs}$ as shown in figure 10. Average speed and acceleration are $36 \mathrm{~km} / \mathrm{h}$ and $0.51 \mathrm{~m} / \mathrm{s}^{2}$ respectively. This drive cycle is suitable for the level of validation done at positive and negative temperatures in the previous section to produce results with good accuracy.

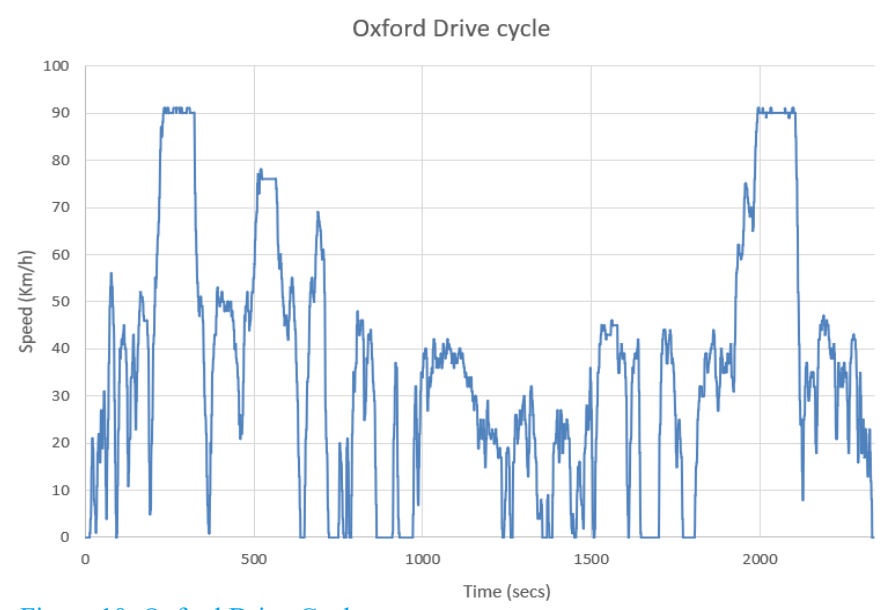

Figure 10. Oxford Drive Cycle. 


\section{Real-World Investigation}

Numerical Simulation of the Validated model is conducted for $-20^{\circ} \mathrm{C}$, $0^{\circ} \mathrm{C}$ and $25^{\circ} \mathrm{C}$ temperatures for the Oxford drive profile and results of the battery parameters are analyzed.

\section{State of Charge (SOC)}

SOC depletion curve for oxford drive cycle is given in figure 11. For comparison purposes, initial SOC is set to $70 \%$ for every test. The SOC at the end of drive profile for $25^{\circ} \mathrm{C}$ and $0^{\circ} \mathrm{C}$ is $62 \%$ and $61.5 \%$ respectively. However, at $-20^{\circ} \mathrm{C}$, SOC drops to $49 \%$ at the end of the cycle. The difference in the final SOC value is $13 \%$ for positive vs negative temperature which is a reduction of $21 \%$ when the vehicle operates in sub-zero temperature. While there is a reduction of $20.3 \%$ when comparing $\mathrm{SOC}$ at $0^{\circ} \mathrm{C}$ and $-20^{\circ} \mathrm{C}$.

Reduction of $21 \%$ in SOC is substantial, considering that HVAC or other auxiliary systems are not included in the numerical model. Also, the difference between $0^{\circ} \mathrm{C}$ and $25^{\circ} \mathrm{C}$ will be bigger if effect of HVAC is added as it is a necessity at $0^{\circ} \mathrm{C}$ and $-20^{\circ} \mathrm{C}$.

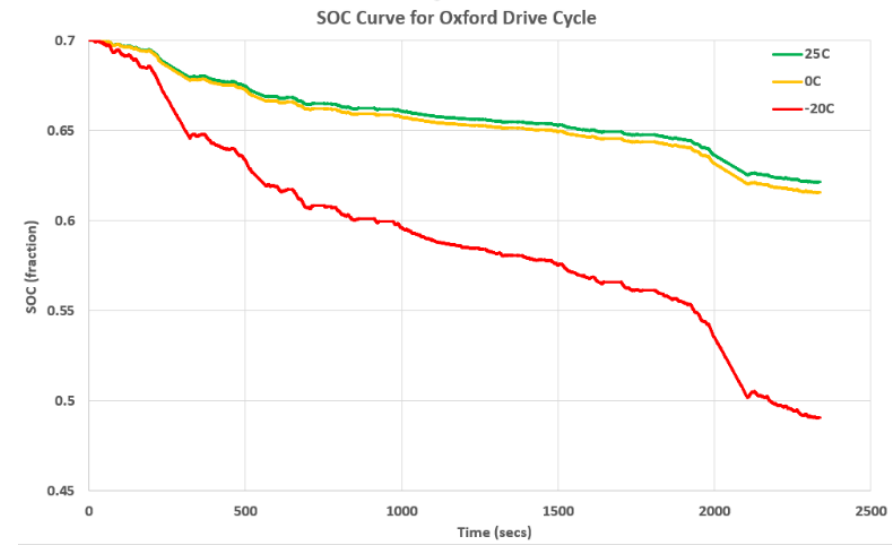

Figure 11. SOC depletion curve for oxford drive cycle.

\section{Efficiency}

Instantaneous efficiency for the real-world drive cycle with respect to time, represented in $\mathrm{kW}-\mathrm{h}$ of energy consumed per $100 \mathrm{~km}$ is given in figure 12(a). Vehicle overcomes static friction when it begins to move from rest which explains the spike in energy consumption at the beginning. Later, the model constantly consumes more energy throughout the cycle at $-20^{\circ} \mathrm{C}$. Figure 12 (b) shows the real-time instantaneous difference of efficiency in percentage for $0^{\circ} \mathrm{C},-20^{\circ} \mathrm{C}$ with $25^{\circ} \mathrm{C}$.

After the initial spike, the model at $0^{\circ} \mathrm{C}$ consumes a constant of around $6.5 \%$ or $1.5 \mathrm{~kW}$-h more instantaneous energy per $100 \mathrm{~km}$ than at $25^{\circ} \mathrm{C}$ and the peak difference is $10.1 \%$. At $-20^{\circ} \mathrm{C}$, model consumes $24.2 \%$ or $4.1 \mathrm{~kW}$-h more instantaneous energy per $100 \mathrm{~km}$ than when it is operated at $25^{\circ} \mathrm{C}$. Maximum difference is $38.6 \%$ in this case. Overall, there is a $17.7 \%$ variation in energy consumption between $25^{\circ} \mathrm{C},-20^{\circ} \mathrm{C}$ and $0^{\circ} \mathrm{C}, 25^{\circ} \mathrm{C}$ which translates to substantial difference in range the model is able to achieve at different temperatures. Such variation in efficiency is not suitable in real-world

Page 11 of 16 operation as it hampers the versatility of EVs in diverse operating conditions.

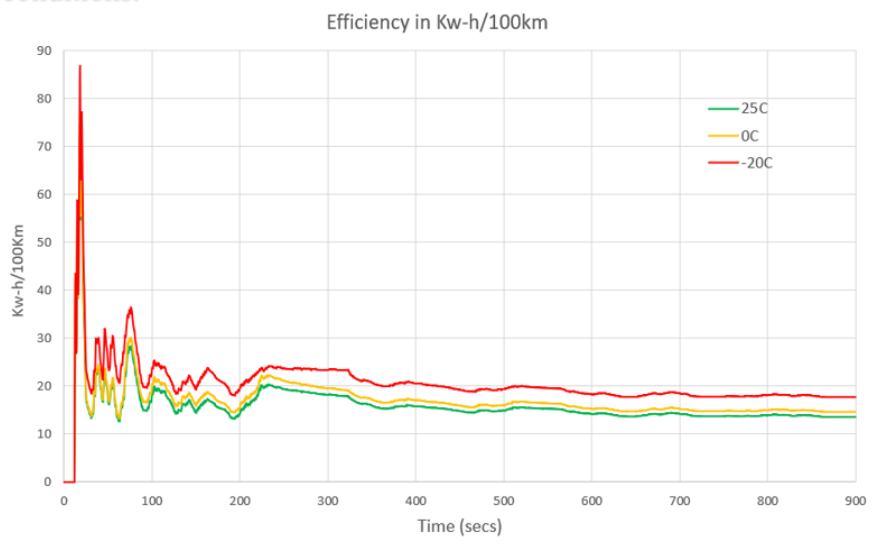

Percentage Difference in Efficiency of 0C, $-20 \mathrm{C}$ with $25 \mathrm{C}$

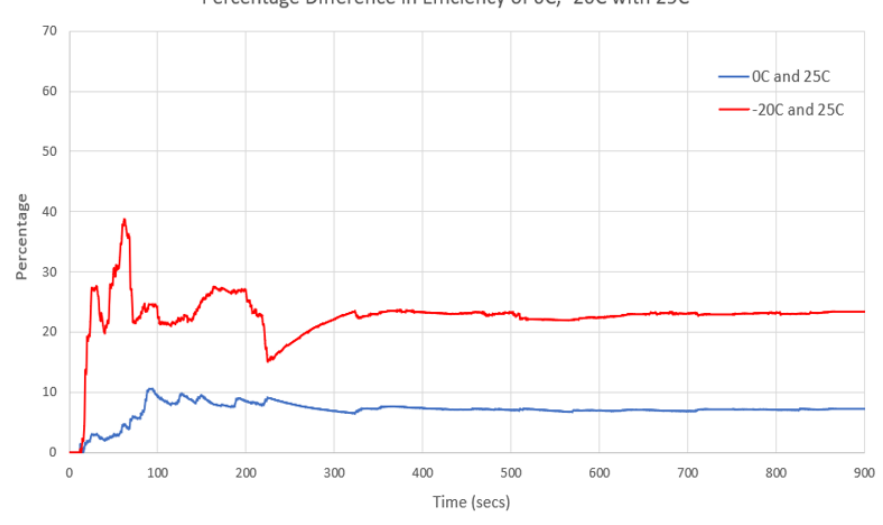

Figure 12. a) Efficiency in $\mathrm{kW}-\mathrm{h}$ per $100 \mathrm{Km}$, b) Percentage difference in energy consumed between $0 \mathrm{C}$ and $-20 \mathrm{C}$ with $25 \mathrm{C}$.

\section{Energy Consumption and Losses}

The model consumes an additional $0.95 \mathrm{KWh}$ more energy at $-20^{\circ} \mathrm{C}$ than at $25^{\circ} \mathrm{C}$ which is a $31.9 \%$ increase in overall energy consumption for the Oxford drive cycle. Whereas at $0^{\circ} \mathrm{C}$, it is 0.21 $\mathrm{KWh}$ which is $7 \%$ more than at $25^{\circ} \mathrm{C}$ as shown in table 5 .

The model estimates battery losses based on energy lost to overcome internal resistant loads due to temperature effects, which is quite high at $-20^{\circ} \mathrm{C}$. Energy losses due Internal resistance increased by $5545 \mathrm{KJ}$, which is around $1.54 \mathrm{kWh}$, when temperature was $-20^{\circ} \mathrm{C}$ compared to $25^{\circ} \mathrm{C}$, which is almost $37.8 \%$ of the total losses in the entire vehicle compared to $8.3 \%$ and $3.9 \%$ total losses at $0^{\circ} \mathrm{C}$ and $25^{\circ} \mathrm{C}$ respectively.

Comparison of the model energy consumption $(\mathrm{Wh} / \mathrm{km})$ for realworld and legislative drive cycles is given in table 6. Energy consumption is highest for US06 as it is an aggressive profile, while it is the least for UDDS at every temperature as it is the least aggressive and is also transient. Second highest energy consumption is seen for HWY cycle which simulates expressway behavior of steady, high speeds. 
Table 5. Energy Consumption and losses for Oxford Drive Cycle.

\begin{tabular}{|c|c|c|c|}
\hline Parameters & $\mathbf{2 5}^{\mathbf{}} \mathbf{C}$ & $\mathbf{0}^{\mathbf{0}} \mathbf{C}$ & $\mathbf{- 2 0}^{\mathbf{0}} \mathbf{C}$ \\
\hline $\begin{array}{c}\text { Overall Energy } \\
\text { Consumption (KJ) }\end{array}$ & 10726 & 11476 & 14151 \\
\hline $\begin{array}{c}\text { Overall Energy } \\
\text { Consumption (kWh) }\end{array}$ & 2.98 & 3.2 & 3.9 \\
\hline $\begin{array}{c}\text { Battery Losses (KJ) } \\
\text { \% Of all losses }\end{array}$ & 3.9 & 8.3 & 37.8 \\
\hline $\begin{array}{c}\text { Electric Machine } \\
\text { losses (KJ) }\end{array}$ & 1461 & 1473 & 1484 \\
\hline \% Of all losses & 13.6 & 12.7 & 9.4 \\
\hline
\end{tabular}

Table 6. Energy consumption (Wh/Km) of Model for different drive cycles.

\begin{tabular}{|c|c|c|c|c|}
\hline $\begin{array}{c}\text { Energy } \\
\text { Consumption } \\
(\mathbf{W h} / \mathbf{K m})\end{array}$ & UDDS & HWY & US06 & $\begin{array}{c}\text { Oxford } \\
\text { Drive Cycle }\end{array}$ \\
\hline $\mathbf{2 5}^{\mathbf{C}}$ & 116 & 144 & 205 & 128 \\
\hline $\mathbf{0}^{\mathbf{0}} \mathbf{C}$ & 121 & 149 & 227 & 137 \\
\hline $\mathbf{- 2 0}^{\mathbf{0}} \mathbf{C}$ & 167 & 206 & 233 & 169 \\
& & & & \\
\hline
\end{tabular}

\section{Internal Resistance}

The internal resistance for the oxford drive cycle is given in figure 13. The average of the internal resistance dataset at $25^{\circ} \mathrm{C}$ is 0.24 ohms, while at $0^{\circ} \mathrm{C}$ and $-20^{\circ} \mathrm{C}$, it is $0.47 \mathrm{ohms}$ and $1.76 \mathrm{ohms}$ respectively. At $0^{\circ} \mathrm{C}$, internal resistance increases by around 0.23 ohms on an average compared to positive temperature, which is a $96 \%$ rise throughout the real-world drive cycle.

The internal resistance at $-20^{\circ} \mathrm{C}$ increases by $1.52 \mathrm{ohms}$ on an average compared to the model operating at $25^{\circ} \mathrm{C}$. This results in a six-fold increase at negative temperatures which translates to considerable degradation of performance of the EV at negative temperatures. Such substantial rise in internal resistance at $-20^{\circ} \mathrm{C}$ is the reason for the increase in energy consumption compared to $25^{\circ} \mathrm{C}$ explained in the previous section.

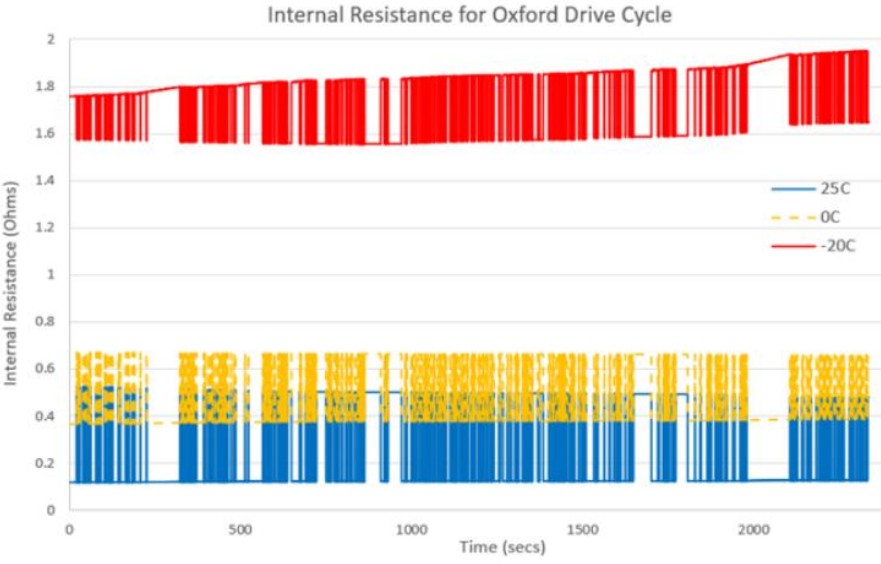

Figure 13. Internal Resistance for Oxford Drive cycle at three temperatures.

\section{Terminal Power}

Terminal power output $(\mathrm{kW})$ of the model is compared at three temperatures and real time simulation graph is given in figure 14(a) for the Oxford cycle. It is clearly visible that the output at $0^{\circ} \mathrm{C}$ and $25^{\circ} \mathrm{C}$ has the highest spikes at every instant of the cycle. In comparison, the $-20^{\circ} \mathrm{C}$ graph is limited to a maximum average of around $15-18 \mathrm{~kW}$. Reduction in temperature in cold weather results in reduced power output, which is evident from this analysis.
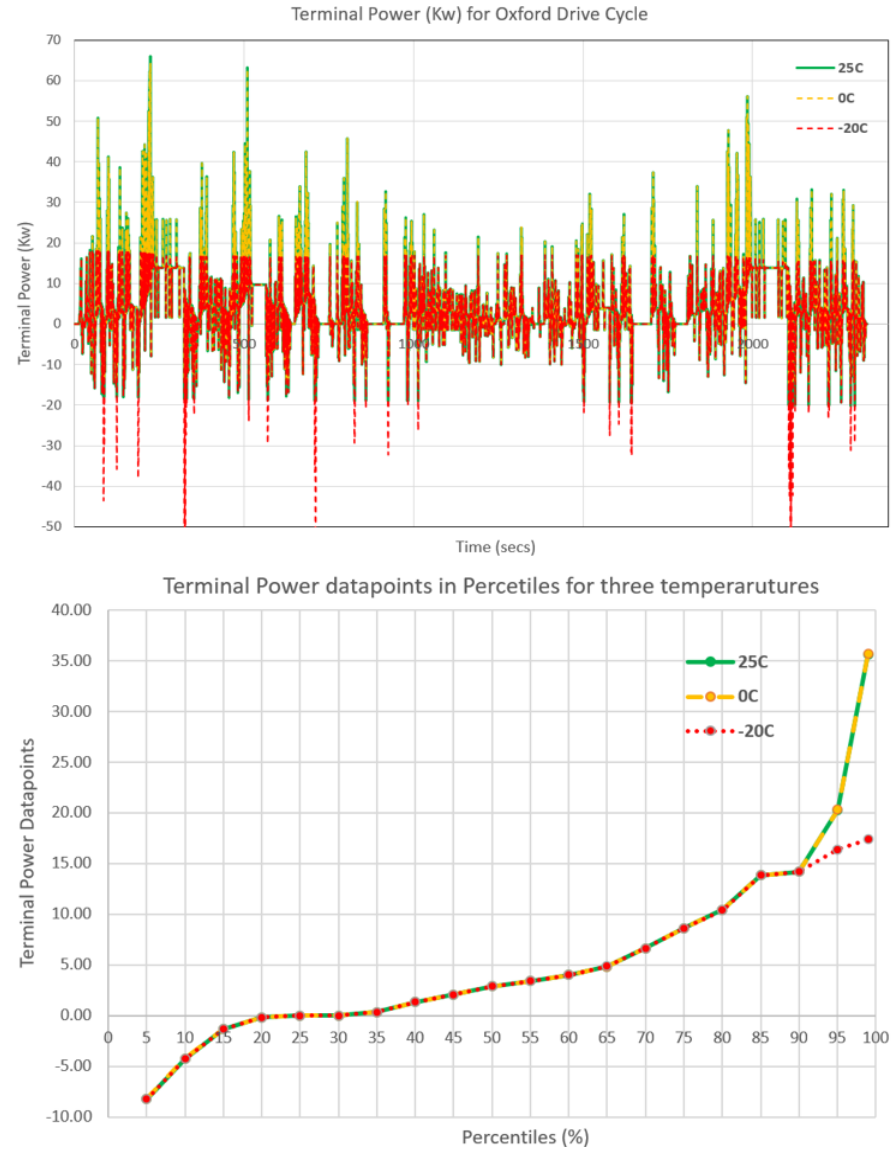

Figure 14. a) Terminal Power Output for Oxford Drive Cycle, b) Power datapoints represented in terms of percentile. 
Another point to be noted here is that, the differences between $0^{\circ} \mathrm{C}$ and $25^{\circ} \mathrm{C}$ terminal power output is not significant as much as it is for sub-zero temperature.

To analyze the output data better, the datapoints at each temperature are categorized in percentiles, given in figure 14(b). There is no significant difference between $0^{\circ} \mathrm{C}$ and $25^{\circ} \mathrm{C}$ for the entire hundred percentile of points, as evident from the first graph. This is similar for $-20^{\circ} \mathrm{C}$ as well until the $90^{\text {th }}$ percentile. It is in the last $10 \%$ of terminal power data points, the model at $-20^{\circ} \mathrm{C}$ manages a maximum of 17 $\mathrm{kW}$, while at $0^{\circ} \mathrm{C}$ and $25^{\circ} \mathrm{C}$, the average maximum power output datapoints are around $36 \mathrm{~kW}$. This translates to roughly $47 \%$ reduction in the model's peak power output capability at $-20^{\circ} \mathrm{C}$. Therefore, at negative temperatures, up to $90 \%$ of the power capabilities are retained, however, the remaining $10 \%$ of peak power of the battery pack is stunted.

\section{Terminal Current}

Real time terminal current output of the numerical model at different temperatures for the Oxford drive profile is given in figure 15(a). It is clearly visible that the model at $-20^{\circ} \mathrm{C}$ is unable to supply higher peak current like it does at $0^{\circ} \mathrm{C}$ and $25^{\circ} \mathrm{C}$ due to the rise of resistive loads as temperatures drop.
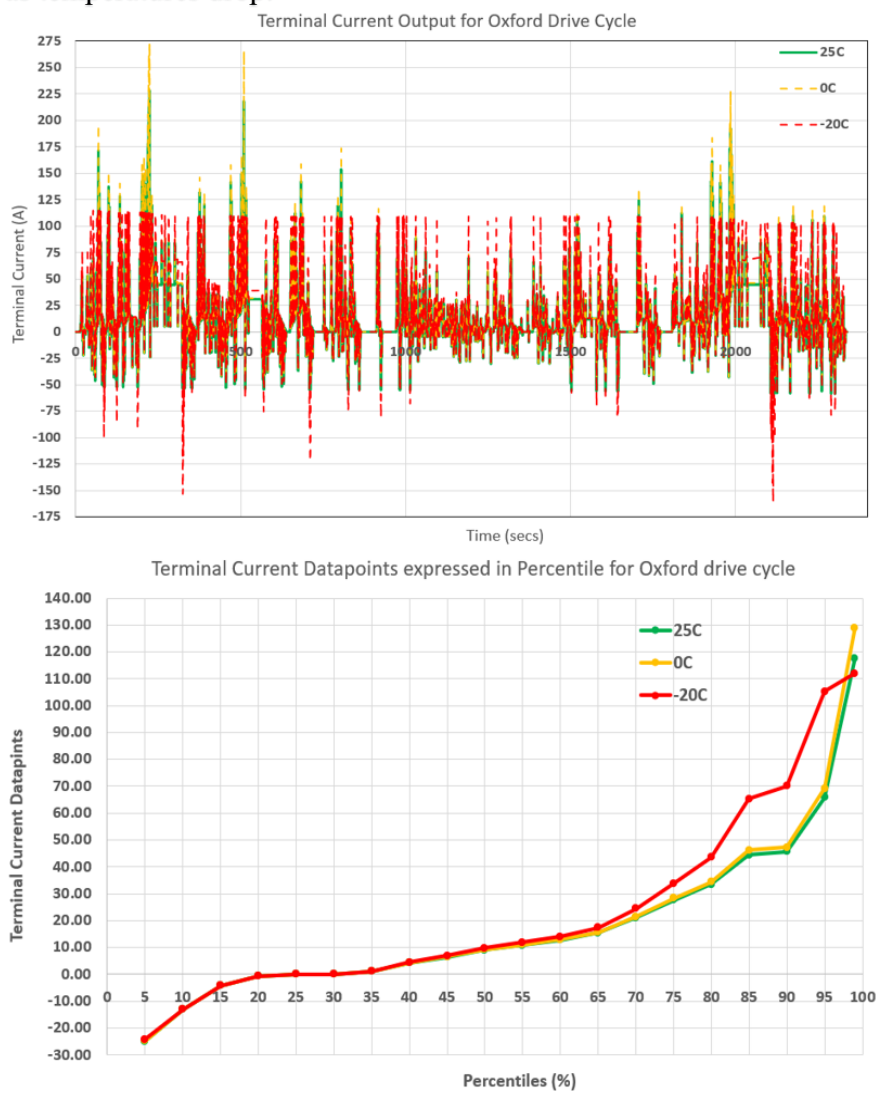

Figure 15. a) Terminal Current Output for Oxford Drive Cycle, b) Terminal Current Datapoints represented in percentile.

Figure 15(b) shows the current datapoints in percentiles. It can be seen that the current datapoints match up to $65 \%$ percentile points or 20 amps for all three temperatures. After this, $-20^{\circ} \mathrm{C}$ curve rises higher than others which indicates that the model at $-20^{\circ} \mathrm{C}$ demands more current comparatively to follow the drive profile as it has to overcome higher resistive loads due to increase in internal resistance at cold temperatures. This results in higher energy consumption and drop in SOC which is evident from the earlier results. Upwards of $95^{\text {th }}$ percentile, the model at $0^{\circ} \mathrm{C}$ and $25^{\circ} \mathrm{C}$ is also able to supply higher peak currents than at $-20^{\circ} \mathrm{C}$.

Addition of auxiliary systems like Battery Thermal Management System (BTMS), pumps and other power electronics in the numerical model are out of scope of this study. Hence, the additional energy that these systems consume is compensated by increasing the battery pack capacity in the model. Originally, BMW i3 has all its $9660 \mathrm{Ah}$ cells stacked in series. However, in the current Model, the 96 cells are arranged in 2 parallel stacks to increase the pack capacity.

\section{Conclusions}

Equivalent Electric Circuit Models (EECM) was found to be the most suitable for evaluating the performance of the Li-ion battery powered $\mathrm{EV}$ in sub-zero temperatures because of their simplicity and their suitability of integration with a vehicle model.

A numerical model based on BMW i3 integrated with a first order EECM parameters are capable of achieving an accuracy of current output more than $92 \%$ while the model predicted SOC with less than $2 \%$ error compared to the ANL data.

For a real-world drive cycle at $-20^{\circ} \mathrm{C}$, the internal resistance of the battery was found to be one of the major causes for higher energy consumption of the battery, lower efficiency, stunted power and current outputs and substantial battery losses at extreme sub-zero temperatures.

The study shows a novel approach to conduct investigations for performance of EVs in real-world conditions using numerical simulations with very limited inputs based on a typical electric vehicle acquired from available established literature.

Page 13 of 16 


\section{References}

1. Leach, F., Kalghatgi, G., Stone, R., and Miles, P., "The scope for improving the efficiency and environmental impact of internal combustion engines," Transportation Engineering, 100005, 2020, doi: $\underline{10.1016 / j . t r e n g .2020 .100005}$

2. Emadi, A., "Transportation 2.0," IEEE Power and Energy Magazine, 9(4):18-29, 2011, doi:10.1109/MPE.2011.941320

3. Gerssen-Gondelach, S. J., and Faaij, A. P., "Performance of batteries for electric vehicles on short and longer term," Journal of power sources 212:111-129, 2012, doi:10.1016/i.jpowsour.2012.03.085

4. "Battery Electric Vehicle Energy Consumption and Range Test Procedure" 2017-07-12, Ground Vehicle Standard J1634, 2017-07, SAE International.

5. Reyes, J. R. M. D., Parsons, R. V., and Hoemsen, R., "Winter happens: The effect of ambient temperature on the travel range of electric vehicles," IEEE Transactions on Vehicular Technology 65(6):4016-4022, 2016, doi: $10.1109 /$ TVT.2016.2544178

6. Ruiz, V., "Standards for the performance and durability assessment of electric vehicle batteries," JRC Technical Reports, 2018.

7. Garabedian, H., and Heafitz, A., "State of the art electric vehicle cold weather range," SAE Technical Paper 971627 , 1997, doi: $\underline{10.4271 / 971627}$

8. Chan, H. L., "A new battery model for use with battery energy storage systems and electric vehicles power systems," at IEEE Power Engineering Society Winter Meeting, Conference Proceedings (Cat. No.00CH37077), (Vol. 1:470-475), Singapore, January 23-27, 2000, doi:10.1109/PESW.2000.850009

9. Jaguemont, J., Boulon, L., and Dubé, Y., "Characterization and modeling of a hybrid-electric-vehicle lithium-ion battery pack at low temperatures," IEEE Transactions on Vehicular Technology 65(1):1-14, 2015, doi:10.1109/TVT.2015.2391053

10. Ravi, V., Jentz, R., Kumar, V. et al., "Assessment of Exhaust Actuator Control at Low Ambient Temperature Conditions," SAE Technical Paper 2021-01-0681, 2021, doi:10.4271/2021-01-0681.

11. Xu, W., Han, Y., Yang, Q. et al., "Battery heating circuit," EP2413465A1, February 1, 2012.

12. Brown, S., Pyke, D., and Steenhof, P., "Electric vehicles: The role and importance of standards in an emerging market," Energy Policy 38(7):3797-3806, 2010, doi: $\underline{10.1016 / \mathrm{j} . e n p o l .2010 .02 .059}$
13. Shiao, H. C. A., Chua, D., Lin, H. P., Slane, S. et al., "Low temperature electrolytes for Li-ion PVDF cells," Journal of power sources 87(1-2):167-173, 2000, doi:10.1016/S0378$\underline{7753(99) 00470-X}$

14. Zhang, S. S., Xu, K., and Jow, T. R., "The low temperature performance of Li-ion batteries," Journal of Power Sources 115(1):137-140, 2003, doi:10.1016/S0378$\underline{7753(02) 00618-3}$

15. Ma, S., Jiang, M., Tao, P., Song, C. et al., "Temperature effect and thermal impact in lithium-ion batteries: A review," Progress in Natural Science: Materials International 28(6):653-666, 2018, doi:10.1016/j.pnsc.2018.11.002

16. Gao, F., and Tang, Z., "Kinetic behavior of LiFePO4/C cathode material for lithium-ion batteries," Electrochimica Acta 53(15):5071-5075, 2008, doi: $10.1016 /$ i.electacta.2007.10.069

17. Gunawardhana, N., Dimov, N., Sasidharan, M., Park, G. J. et al., "Suppression of lithium deposition at sub-zero temperatures on graphite by surface modification," Electrochemistry communications 13(10):1116-1118, 2011, doi:10.1016/j.elecom.2011.07.014

18. Awarke, A., Jaeger, M., Oezdemir, O., and Pischinger, S., "Thermal analysis of a Li-ion battery module under realistic EV operating conditions," International Journal of Energy Research 37(6):617-630, 2013, doi:10.1002/er.2884.

19. Baronti, F., Fantechi, G., Leonardi, E., Roncella, R., and Saletti, R., "Enhanced model for Lithium-Polymer cells including temperature effects," IECON 2010 - 36th Annual Conference on IEEE Industrial Electronics Society, USA, Nov 7-10, 2010, doi:10.1109/IECON.2010.5675134

20. Zhu, D., Pritchard, E. G. D., and Silverberg, L. M., "A New System Development Framework Driven by a ModelBased Testing Approach Bridged by Information Flow," IEEE Systems Journal 12(3):2917-2924, 2016, doi:10.1109/JSYST.2016.2631142.

21. Fotouhi, A., Auger, D. J., Propp, K., Longo, S., and Wild, M., "A review on electric vehicle battery modelling: From Lithium-ion toward Lithium-Sulphur," Renewable and Sustainable Energy Reviews 56:1008-1021, 2016, doi:10.1016/j.rser.2015.12.009

22. Zhang, C., Li, K., Mcloone, S., and Yang, Z., "Battery modelling methods for electric vehicles - A review," presented at 2014 European Control Conference (ECC), France, June 24-27, 2014, doi:10.1109/ECC.2014.6862541

23. Chen, M., and Rincon-Mora, G. A., "Accurate electrical battery model capable of predicting runtime and IV performance," IEEE transactions on energy conversion 21(2):504-511, 2006, doi:10.1109/TEC.2006.874229 
24. Kroeze, R. C., and Krein, P. T., "Electrical battery model for use in dynamic electric vehicle simulations," presented at 2008 IEEE Power Electronics Specialists Conference, Greece, June 15-19, 2008, doi: 10.1109/PESC.2008.4592119

25. Zhang, H., and Chow, M. Y., "Comprehensive dynamic battery modeling for PHEV applications," presented at IEEE PES General Meeting, USA, July 25-29, 2010, doi:10.1109/PES.2010.5590108

26. Hu, X., Li, S., and Peng, H., "A comparative study of equivalent circuit models for Li-ion batteries," Journal of Power Sources 198:359-367, 2012, doi:10.1016/i.jpowsour.2011.10.013

27. Huria, T., Ceraolo, M., Gazzarri, J., and Jackey, R., "High fidelity electrical model with thermal dependence for characterization and simulation of high power lithium battery cells," presented at 2012 IEEE International Electric Vehicle Conference, USA, March 4-8, 2012, doi: 10.1109/IEVC.2012.6183271

28. Argonne National Laboratory, "Energy Systems D3 2014 BMW i3BEV," Energy Systems Division, https://www.anl.gov/es/energy-systems-d3-2014-bmwi3bev, accessed June 2020.

29. BMW Group, "Technical Specifications of the BMW i3," https://www.press.bmwgroup.com/global/article/detail/T02 $\underline{85608 \mathrm{EN} / \text { technical-specifications-of-the-bmw-i3-120-ah- }}$ and-the-bmw-i3s-120-ah-valid-from-11/2018?language=en, accessed June 2020.

30. BARLOW, T. J., Latham, S., McCrae, I. S., and Boulter, P. G., "A reference book of driving cycles for use in the measurement of road vehicle emissions," (TRL Published Project Report, 2009), ISSN: 0968-4093, https://assets.publishing.service.gov.uk/government/upload s/system/uploads/attachment data/file/4247/ppr-354.pdf.

\section{Contact Information}

\section{Mohammad Tahir Baig}

Oxford Brookes University mdtahir.baig03@gmail.com +91-9989467137

Stephen Samuel Oxford Brookes University s.samuel@brookes.ac.uk 
Appendix

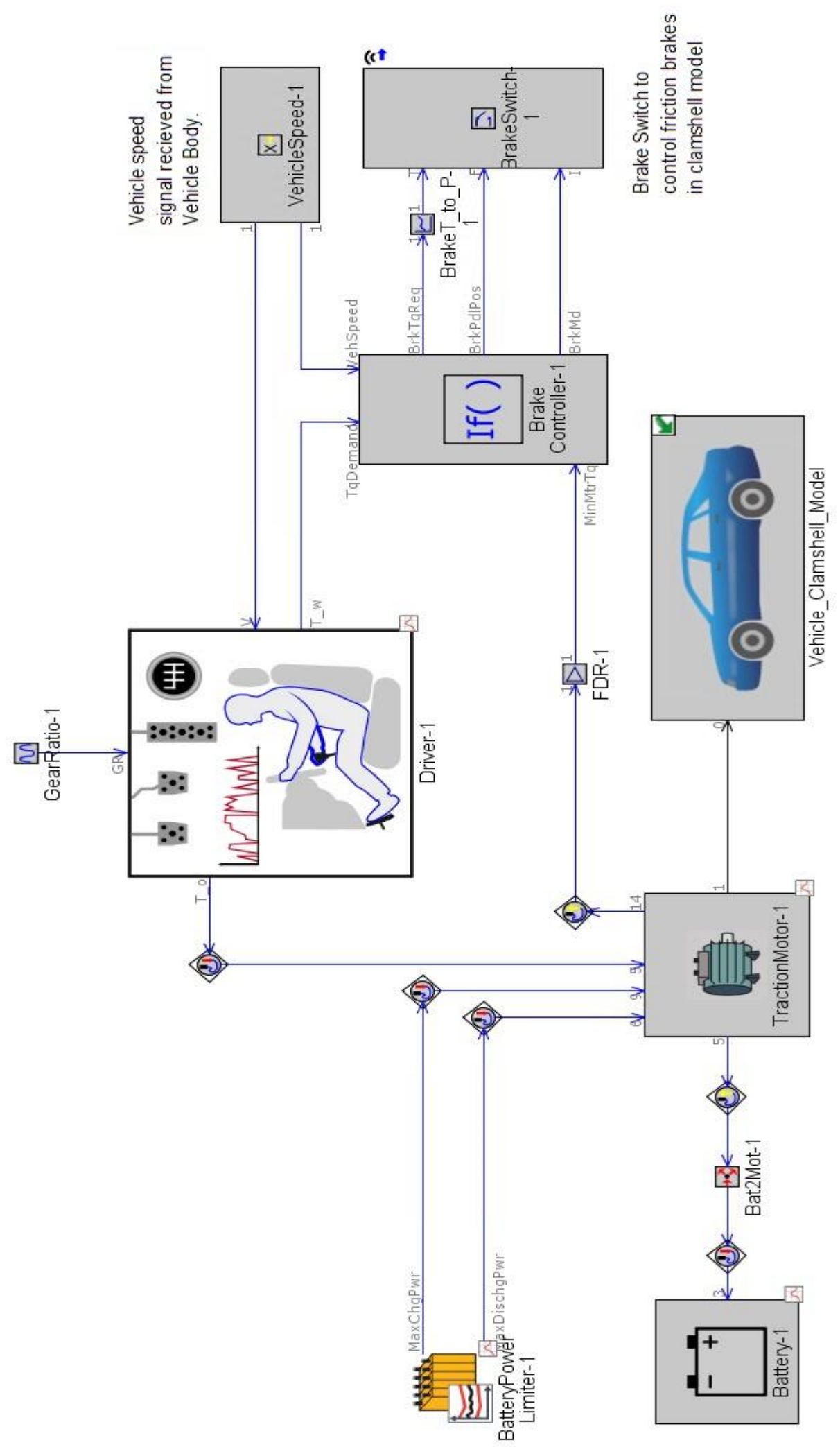

Figure A1 Schematic of Numerical model 